\title{
Performance and Fracture Analysis of Composite Interfaces for Semi-Flexible Pavement
}

\author{
Kuanghuai Wu (D), Xiaoyu Liu, Xu Cai *D, Wenke Huang, Jinlou Yu and Guihai Nie
}

check for updates

Citation: Wu, K.; Liu, X.; Cai, X.;

Huang, W.; Yu, J.; Nie, G.

Performance and Fracture Analysis of

Composite Interfaces for

Semi-Flexible Pavement. Coatings

2021, 11, 1231. https://doi.org/

10.3390/coatings11101231

Academic Editor: Valeria Vignali

Received: 16 September 2021

Accepted: 6 October 2021

Published: 9 October 2021

Publisher's Note: MDPI stays neutral with regard to jurisdictional claims in published maps and institutional affiliations.

Copyright: (c) 2021 by the authors. Licensee MDPI, Basel, Switzerland. This article is an open access article distributed under the terms and conditions of the Creative Commons Attribution (CC BY) license (https:// creativecommons.org/licenses/by/ $4.0 /)$.
School of Civil Engineering, Guangzhou University, Guangzhou 510006, China; wukuanghuai@163.com (K.W.); liuxiaoyugd@163.com (X.L.); h.wenke@gzhu.edu.cn (W.H.); 13258583735@163.com (J.Y.); 13022003080@163.com (G.N.)

* Correspondence: cx_caixu@163.com

\begin{abstract}
Semi-flexible pavement is widely used in pavement engineering due to its excellent rutting resistance; however, it mainly fails due to cracking. Therefore, it is important to understand the properties of the aggregate-mortar-asphalt interfacial transition zone, to better understand the cracking mechanism of the semi-flexible pavement. In this work, we used pull-off tests and digital image analysis technology to compare and analyze the interfacial tensile strength and granitebitumen-mortar interactions in three types of asphalt (70\# matrix asphalt, PG76-22 modified asphalt and S-HV modified asphalt) at different curing ages. The analysis results showed that, for the three different bitumen materials, with settled mortar, the peak interfacial tensile strength values all occurred at approximately $14 \mathrm{~d}$ of curing. In addition, the order of the tensile strength followed the order of asphalt penetration degree; the order of the interfacial water damage resistance from weak to strong was 70\# asphalt cementation specimen, PG76-22 modified asphalt cementation specimen, and S-HV modified asphalt cementation specimen. The results of this analysis highlight the original contributions of the optimum curing time for the composite interface of semi-flexible pavement materials prepared with different asphalts to reach optimum crack resistance.
\end{abstract}

Keywords: semi-flexible pavement; composite interface; fracture analysis

\section{Introduction}

Semi-flexible pavement (SFP) refers to composite pavements that have characteristics of both asphalt and cement concrete, and are formed by filling a special slurry with cement as the main component in the open-graded asphalt mixture with a large void matrix [1-4]. Semi-flexible pavements are also known as semi-rigid pavements, grouted macadam composite materials, cement grout asphalt composites, asphalt-Portland cement concrete composites (APCCC), and composite cement-asphalt mixtures [5]. The SFP is constructed without the use of expansion, contraction, and construction joints and demonstrates prominent rutting and shoving-corrugation resistance. These new pavement materials possess both the flexible characteristics of asphalt pavement and the high strength (hardness) of concrete pavement [5]. As a result, they have broad application prospects, such as overloaded road surfaces, intersections, and bus stations [6]. However, cracking is the main problem that hinders the acceptance of semi-flexible pavements [7]. In addition, the interfacial bonding strength of the composite material will affect its overall performance [8], and the semi-flexible pavement mortar-asphalt interface is considered the weak link.

In 1960, SFP was first successfully used as airport pavement in France [2,9]. Ever since, there have been numerous studies on the structural design and engineering properties of SFP materials, and the corresponding grouting cement mortar [6,10-14]. Cihackova [15] used wheel tracking, stiffness modules, skid resistance, and low-temperature cracking tests and found that the resistance of SFP against rutting is considerably higher than asphalt mixtures. However, the resistance of SFP against low-temperature cracking is lower than asphalt mixtures. Corradini [16] et al. studied the fatigue properties of SFP by indirect 
tensile testing, utilizing cylindrical specimens that were directly cored from the existing pavement. This method evaluated the in situ behavior of the materials and found that the SFP had a remarkably longer fatigue life compared to regular asphalt mixtures. Read and Collop also found that, under the recommended test conditions (120 ms loading time and test temperature less than $30^{\circ} \mathrm{C}$ ), tensile failure was the dominant failure mode in the asphalt mixture specimens [17].

The formation of low-temperature cracks can affect pavement performance, as well as lead to a serious reduction in service life [15,18-20]. Semi-flexible pavement materials are a combination of organic and inorganic composite materials, and the SFP interface will directly affect its mechanical properties and road performance. In practical applications, this type of pavement structure will easily crack and have poor fatigue resistance, mainly due to weak interfacial bonding [21]. However, there have been few studies on SFP interfaces and how they affect its material properties. Hou et al. showed that the crack paths will appear along the interface between the asphalt-coated aggregates and the hardened $\mathrm{CP}$. This was attributed to a poor bonding strength between the hardened $\mathrm{CP}$ and bitumen binder [22]. Xu et al. also used three types of interface modifiers to optimize the asphalt-mortar interface, showing that the pavement performance of the SFP was affected by the bond strength of the cement-asphalt interface, and poor contact at the interface caused insufficient strength and poor deformation [23]. Zhou analyzed the failure mode of SFPM, and showed that damage in SFP usually occurs at the interface between the cement and asphalt, and damage from the cement itself $[23,24]$. Hou et al. also found that the cement paste is stiffer than the asphalt mixture, resulting in a significant difference in the interfacial bonding properties and the elastic modulus of the matrix asphalt mixture in the SFP, leading to a reduction in the strength and tensile strain of the SFP [22]. Cai et al. identified two characteristics in SFP by employing micromechanical models and nanotechniques, including nanoindentation (NI), scanning electron microscopy (SEM), and energy dispersive spectrum analysis (EDS). The results showed there were four different layers in the asphalt phase of the SFP, and the interface of the asphalt-cement phase was more complex than the aggregate-asphalt mastic phase [21].

According to the previous studies, the SFP will have high resistance to rutting and better moisture stability than conventional asphalt mixture; however, its low-temperature cracking resistance will decrease due to the brittleness of the hardened cement paste [24]. Hence, the adhesion between the grouting materials and the bituminous binder is a crucial parameter for evaluating the resistance of crack-induced damages. Owing to its poor lowtemperature cracking resistance, SFP is only suitable for use in some regions. Therefore, to utilize SFP in more areas of the world, the bonding performance of the composite interface in the SFP needs to be investigated.

To assess the interfacial bonding performance of the SFP, this study used a pull-off test and digital image analysis technology to analyze the granite-asphalt mortar specimens at different curing times to assess the interface interactions and tensile strength. In addition, we determine bonding strength changes with the curing age of the asphalt-mortar interface, to determine the best curing time for the different asphalts used in SFP.

\section{Experimental}

The materials used in this study consisted of bitumen, granite, and cement mortar.

\subsection{Raw Materials}

\subsubsection{Bitumen}

The bitumen materials used for the surface of aggregate were 70\# petroleum bitumen, PG76-22 modified asphalt, and S-HV modified asphalt, all produced by Shell Xinyue (Foshan) Asphalt Co., Ltd. (Guangzhou, China). The basic properties of three bitumen materials are given in Tables 1-3 [25]. 
Table 1. Properties of the 70\# petroleum bitumen.

\begin{tabular}{ccc}
\hline Properties & Technical Requirements & Testing Results \\
\hline Penetration @25 ${ }^{\circ} \mathrm{C}, 100 \mathrm{~g}, 5 \mathrm{~s},(0.1 \mathrm{~mm})$ & $60-80$ & 71.8 \\
Softening point R\&B $\left({ }^{\circ} \mathrm{C}\right)$ & $>43$ & 50 \\
Ductility @10 ${ }^{\circ} \mathrm{C}, 5 \mathrm{~cm} / \mathrm{min},(\mathrm{cm})$ & $>20$ & 49.4 \\
Flash point $\left({ }^{\circ} \mathrm{C}\right)$ & $\geq 260$ & 328 \\
Solubility in trichloroethylene $(\%)$ & $\geq 99.5$ & 99.7 \\
Density $@ 15{ }^{\circ} \mathrm{C}\left(\mathrm{g} / \mathrm{cm}^{3}\right)$ & Measured record & 1.040 \\
\hline
\end{tabular}

Table 2. Properties of the PG76-22-modified asphalt.

\begin{tabular}{ccc}
\hline Properties & $\begin{array}{c}\text { Technical } \\
\text { Requirements }\end{array}$ & $\begin{array}{c}\text { Testing } \\
\text { Results }\end{array}$ \\
\hline Penetration $@ 25{ }^{\circ} \mathrm{C}, 100 \mathrm{~g}, 5 \mathrm{~s},(0.1 \mathrm{~mm})$ & $40-60$ & 54.4 \\
Softening point $\mathrm{R} \&\left({ }^{\circ} \mathrm{C}\right)$ & $>70$ & 88.6 \\
Ductility $@ 5^{\circ} \mathrm{C}, 5 \mathrm{~cm} / \mathrm{min},(\mathrm{cm})$ & $>20$ & 32 \\
Penetration index $(\mathrm{PI})$ & $\geq 0$ & 0.06 \\
Elastic recovery ratio @25 ${ }^{\circ} \mathrm{C}(\%)$ & $\geq 90$ & 95 \\
Locomotion viscosity @135 ${ }^{\circ} \mathrm{C}(\mathrm{Pa} . \mathrm{s})$ & $\leq 3.0$ & 2.362 \\
Evaporation residue (softening point) @163 ${ }^{\circ} \mathrm{C}$ for $48 \mathrm{~h}\left({ }^{\circ} \mathrm{C}\right)$ & $\leq 2.5$ & 1 \\
Flash point $\left({ }^{\circ} \mathrm{C}\right)$ & $\geq 230$ & $\geq 230$ \\
Solubility in trichloroethylene $(\%)$ & $\geq 99$ & $\geq 99$ \\
\hline
\end{tabular}

Table 3. Properties of the S-HV-modified asphalt.

\begin{tabular}{ccc}
\hline Properties & $\begin{array}{c}\text { Technical } \\
\text { Requirements }\end{array}$ & Testing Results \\
\hline Penetration $@ 25{ }^{\circ} \mathrm{C}, 100 \mathrm{~g}, 5 \mathrm{~s},(0.1 \mathrm{~mm})$ & $\geq 40$ & 48.1 \\
Softening point $\& \mathrm{~B}\left({ }^{\circ} \mathrm{C}\right)$ & $\geq 80$ & 93 \\
Ductility $@ 5{ }^{\circ} \mathrm{C}, 5 \mathrm{~cm} / \mathrm{min},(\mathrm{cm})$ & $\geq 20$ & 31.5 \\
Elastic recovery ratio @ $25{ }^{\circ} \mathrm{C}(\%)$ & $\geq 85$ & $\geq 85$ \\
Locomotion viscosity @60 ${ }^{\circ} \mathrm{C}(\mathrm{Pa} . \mathrm{s})$ & $>200,000$ & $>200,000$ \\
Evaporation residue (Softening Point) @163 ${ }^{\circ} \mathrm{C} 48 \mathrm{~h}\left({ }^{\circ} \mathrm{C}\right)$ & $\leq 2.5$ & 1.5 \\
Flash point $\left({ }^{\circ} \mathrm{C}\right)$ & $\geq 230$ & $\geq 230$ \\
Solubility in trichloroethylene $(\%)$ & $\geq 99$ & $\geq 99$ \\
\hline
\end{tabular}

\subsubsection{Test Aggregates}

Granite was selected as the test aggregate. As a type of magmatic rock, granite is mainly composed of feldspar, quartz, biotite, and other minerals and, owing to its high density, it has a denser texture and good thermal stability. When heated in an oven, some of the water was removed before reacting, as the material exhibits poor physical permeability and poor water absorption. When placed in a curing box at greater than $80 \%$ humidity, the material will not absorb a considerable amount of water. Thus, the moisture will not penetrate the asphalt interface from the aggregate; otherwise, it could affect the test results. The basic physical properties of granite are shown in Table 4 , and the granite used in this work were pitted granite, which was purchased from the Guangzhou Stone Market. The granite specimens were formed by a double-sided cutting machine in the laboratory, and the cutting machine is shown in Figure 1 . The molded granite specimen was $4 \mathrm{~cm} \times 3 \mathrm{~cm} \times 3 \mathrm{~cm}$ in size, and the specimen is shown in Figure 2 . 


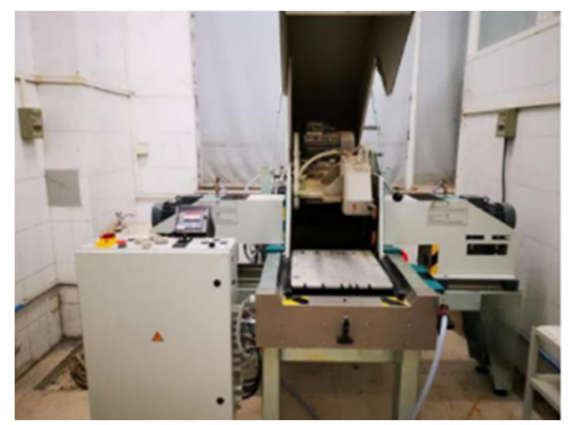

Figure 1. Cutting machine.

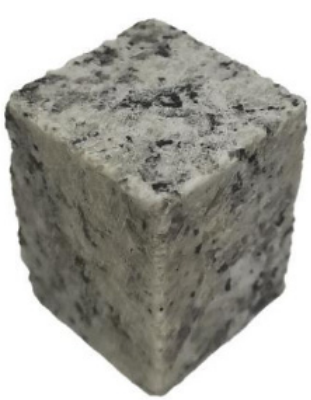

Figure 2. The granite specimen.

Table 4. Properties of the granite.

\begin{tabular}{ccc}
\hline Physical Properties & Technical Requirements & Testing Results \\
\hline Density $\left(\mathrm{kg} / \mathrm{m}^{3}\right)$ & $2790 \sim 3070$ & 2860 \\
Compressive strength $\left(\mathrm{kg} / \mathrm{m}^{2}\right)$ & $1000 \sim 3000$ & 2756 \\
Elastic modulus $(\mathrm{Mpa})$ & $(1.3 \sim 1.5) \times 10^{6}$ & $1.37 \times 10^{6}$ \\
Bibulous rate & $<0.13$ & 0.08 \\
Shore hardness & $>\mathrm{HS} 70$ & HS 89 \\
Proportion & $2.6 \sim 2.75$ & 2.64 \\
\hline
\end{tabular}

\subsubsection{Cement Mortar}

The mortar was prepared using water, cement, and special additives (including sand), which was provided by Guangdong Longhu Technology Co., Ltd. (Shantou, China) [26], using a ratio of 0.23 of water to powder (cement and additives), and a cement/additive ratio of 45:55 to produce the cement mortar. An image of the prepared mortar is shown in Figure 3.

This work utilized white Portland cement, and the initial setting time of the test piece was no longer than $45 \mathrm{~min}$, with a final setting time of no longer than $390 \mathrm{~min}$, and a standard strength grade of $42.5 \mathrm{R}$. The chemical composition and physical properties are shown in Tables 5-7. 


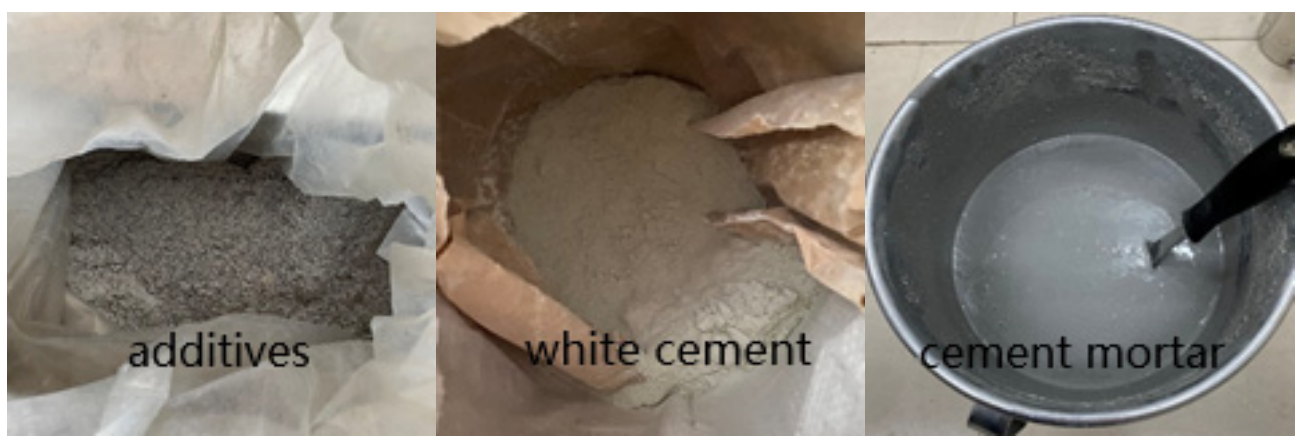

Figure 3. Cement mortar and raw materials.

Table 5. Properties of the Portland cement.

\begin{tabular}{ccccc}
\hline Mineral Composition & $\mathrm{C}_{3} \mathbf{S}$ & $\mathrm{C}_{2} \mathbf{S}$ & $\mathrm{C}_{3} \mathrm{~A}$ & $\mathrm{C}_{4} \mathrm{AF}$ \\
\hline Proportion (\%) & 50.12 & 26.65 & 8.53 & 14.7 \\
\hline
\end{tabular}

Table 6. Properties of the Portland cement.

\begin{tabular}{ccccccccccc}
\hline $\begin{array}{c}\text { Chemical } \\
\text { Composition }\end{array}$ & $\mathrm{CaO}$ & $\mathrm{AL}_{2} \mathrm{O}_{3}$ & $\mathrm{MgO}$ & $\mathrm{SO}_{3}$ & $\mathrm{SiO}_{2}$ & $\mathrm{Na}_{2} \mathrm{O}$ & $\mathrm{K}_{2} \mathrm{O}$ & $\mathrm{Fe}_{2} \mathrm{O}_{3}$ & $\begin{array}{c}\text { Insoluble } \\
\text { Matter }\end{array}$ & $\begin{array}{c}\text { Loss on } \\
\text { Ignition }\end{array}$ \\
\hline Proportion (\%) & 65.44 & 5.51 & 1.99 & 0.50 & 21.51 & 0.12 & 0.48 & 4.88 & 0.09 & 0.48 \\
\hline
\end{tabular}

Table 7. Properties of the Portland cement.

\begin{tabular}{ccc}
\hline \multicolumn{2}{c}{ Physical Properties } & Results \\
\hline \multicolumn{2}{c}{ Density $\left(\mathrm{kg} / \mathrm{m}^{3}\right)$} & 311 \\
\hline Specific surface area $\left(\mathrm{m}^{2} / \mathrm{kg}\right)$ & 345 \\
\hline Water requirement for normal consistency $(\%)$ & 23.8 \\
\hline \multirow{2}{*}{ Compressive strength $(\mathrm{MPa})$} & $7 \mathrm{~d}$ & 40.1 \\
\cline { 2 - 3 } & $28 \mathrm{~d}$ & 59.5 \\
\hline \multirow{2}{*}{ Flexural strength $(\mathrm{MPa})$} & $7 \mathrm{~d}$ & 8.2 \\
\cline { 2 - 3 } & $28 \mathrm{~d}$ & 16.6 \\
\hline
\end{tabular}

\subsection{Specimen Preparation}

2.2.1. Forming the Asphalt Film on the Granite Surface

After using a cutting machine (TNS Infratest Testing Systems CO., LTD., Munich, Germany) to shape the specimen, we used a high-pressure water gun to rinse the surface. We then placed the granite specimen in an oven at $135^{\circ} \mathrm{C}$ and dehydrated it for $6 \mathrm{~h}$. The specimen was then marked and weighed as granite specimen $m_{0}$. Then, the temperature was adjusted to $175^{\circ} \mathrm{C}$ and the specimen was heated for $2 \mathrm{~h}$.

The 70\# petroleum asphalt, PG76-22-modified asphalt, and S-HV-modified asphalt were prepared and placed in the oven for the test. The upper surface of the heated granite specimen was placed on the asphalt for 3-5 s. Then, the upper surface of the granite specimen was attached to a layer of asphalt.

We then placed the granite specimen with the accompanying asphalt layer in the oven, and placed the 70\# petroleum asphalt specimen in the oven at $135^{\circ} \mathrm{C}$. In addition, the S-HV modified asphalt and PG76-22 modified asphalt specimens attached were placed in the oven at $165^{\circ} \mathrm{C}$ and heated for $20 \mathrm{~min}$, causing the asphalt to flow freely and evenly on the upper surface of the granite specimen, forming a relatively uniform asphalt film. 
Finally, the asphalt-coated granite specimen was cooled for one hour. Then, we weighed the asphalt-coated granite specimen $\left(m_{1}\right)$, using Equation (1) to calculate the asphalt film thickness $(d)$

$$
d=\frac{m_{1}-m_{0}}{A \rho}
$$

where $d$ is the asphalt film thickness $(\mu \mathrm{m}), m_{0}$ is the weight of the granite specimen $(\mathrm{g})$, $m_{1}$ is the weight of the granite specimen with the asphalt film $(\mathrm{g}), A$ is the area of granite covered with asphalt $\left(\mathrm{cm}^{2}\right)$, and $\rho$ is the density of the asphalt $\left(\mathrm{g} / \mathrm{cm}^{3}\right)$. The film thickness is shown in Table 8, and the molded test piece is shown in Figure 4.

Table 8. Asphalt film thickness on the granite surface.

\begin{tabular}{cccc}
\hline Asphalt Type & $\begin{array}{c}\text { 70\# Petroleum } \\
\text { Asphalt }\end{array}$ & $\begin{array}{c}\text { PG76-22 Modified } \\
\text { Asphalt }\end{array}$ & $\begin{array}{c}\text { S-HV Modified } \\
\text { Asphalt }\end{array}$ \\
\hline Film thickness $(\mu \mathrm{m})$ & 46.4 & 56.7 & 147.3 \\
\hline
\end{tabular}

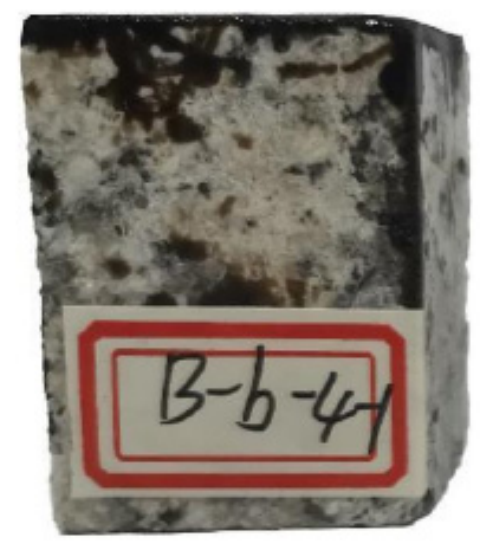

Figure 4. Granite specimen after pouring asphalt.

\subsubsection{Preparing Mortar and Test Specimen}

Cement mortar samples were prepared according to the JGJ/T 70-2009 standard [27]. First, we formed the mold before pouring the mixture, which was cut into a square piece with a side length of $3 \mathrm{~cm}$ using a sandwich wood board, as shown in Figure 5a. We then used an oil-based pen and a steel ruler to measure $1.1 \mathrm{~cm}$ on the small wooden block and marked the scale. Then, a $0.5 \mathrm{~cm}$ wide tape was used to fix the small wooden block and form the mold according to the scale line. Note that the small wooden blocks were sealed without leaving any gaps during splicing; otherwise, the mortar would leak out of the gap when pouring the mortar. The test piece is shown in Figure $5 \mathrm{~b}$.

Then, we poured the prepared cement mortar into the mold and allowed it to cure at room temperature for $24 \mathrm{~h}$. Afterward, it was placed in a constant temperature curing box with greater than $95 \%$ humidity, and at a temperature of $20^{\circ} \mathrm{C}$ for $24 \mathrm{~h}$. The mold was then removed, and the test piece was placed in the curing box. After aging for a prescribed time, the test piece was removed, and a layer of mortar was scraped off the surface of the test piece with a utility knife. Then, we used sandpaper to reduce the mortar to a thickness of $1 \mathrm{~cm} \pm 0.1 \mathrm{~cm}$, as shown in Figure 5b. Afterward, we used AB glue to glue the mold at both ends of the test piece, as shown in Figure 5c. The final test specimen is shown in Figure 5d. 


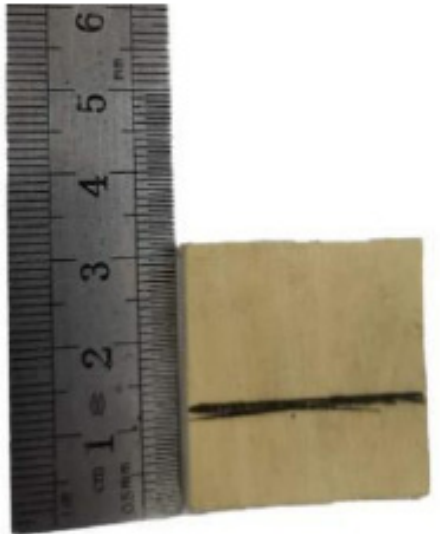

(a)

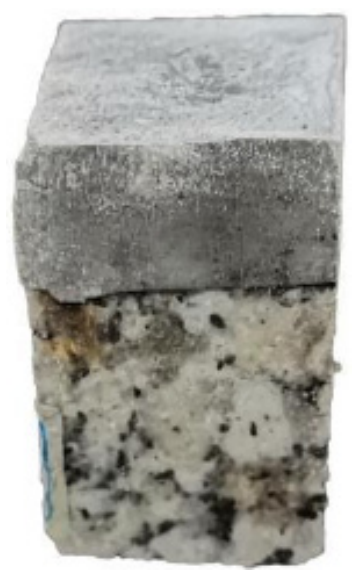

(c)

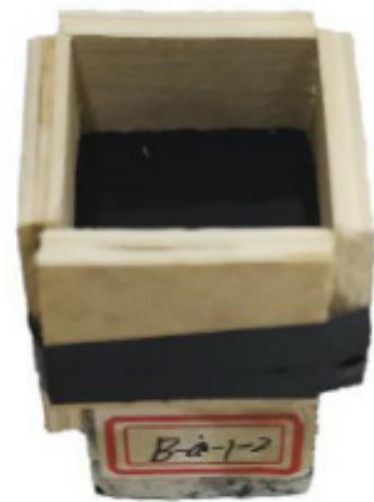

(b)

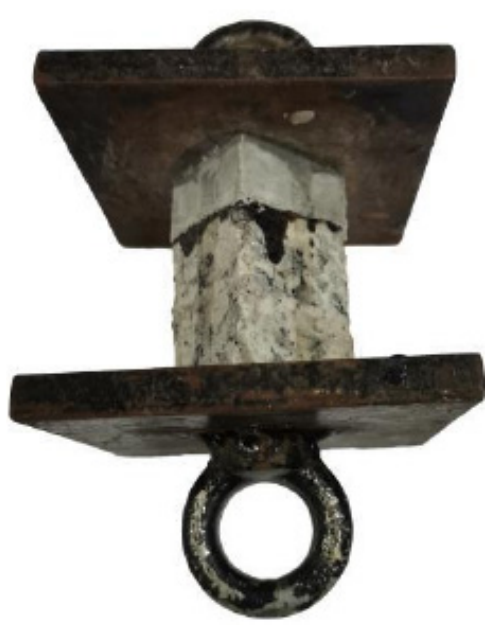

(d)

Figure 5. Preparation of the mortar and test specimens. (a) Sandwich wood board, (b) Granite specimen covered with the mold, (c) Test specimen (d) Specimen ready for pull-off test.

\subsection{Methods}

\subsubsection{Pull-Off Test}

As shown in Figure 6, we used a universal testing machine (MTS SYSTEMS (CHINA) CO., LTD. Shenzhen, China) to perform the uniaxial tensile test with a pull rate of $1 \mathrm{~mm} / \mathrm{min}$, and we measured the peak force.

To control for errors, three sets of tests were conducted for each test condition in this work, and we calculated the average of three test results. If the ratio of the average to the maximum and minimum was greater than $15 \%$, the test value was considered invalid and the test was rerun, especially if one of the ratios was greater than $10 \%$, and the other was less than $10 \%$, whichever was smaller. The average of each value was used as the test result, and when the ratio was between $15 \%$ and $10 \%$, the median of the three values was taken as the test result. If the ratio was less than $10 \%$, the average of the three values was taken as the test result. 


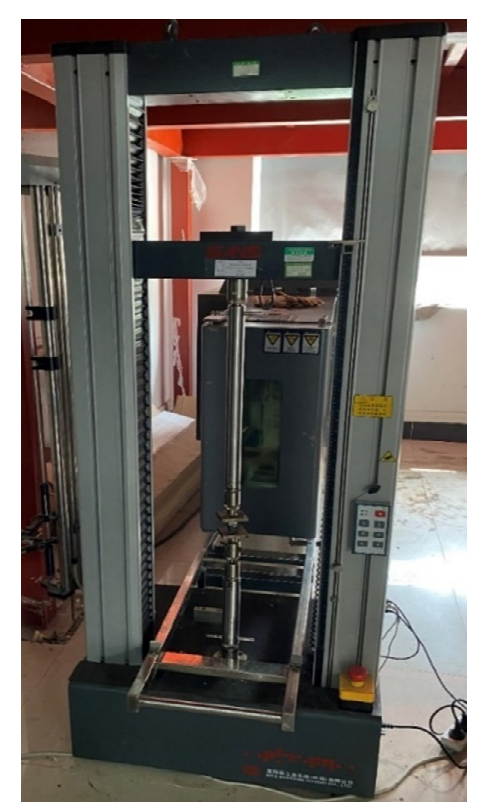

Figure 6. Universal testing machine.

Before starting the test, we placed the test specimen in a $25^{\circ} \mathrm{C}$ constant-temperature curing box for $12 \mathrm{~h}$ to control the test variables to reduce error. The specimen interface stress, Rm, was calculated by Equation (2):

$$
R_{m}=\frac{F_{p}}{A}
$$

where $R_{m}$ is the stress at the interface (MPa), $F_{p}$ is the peak force at the interface $(\mathrm{N})$, and $A$ is the interface area $\left(\mathrm{cm}^{2}\right)$.

\subsubsection{Digital Image Processing Technology}

To evaluate the adhesion behavior of the asphalt-mortar on the fractal surface more accurately, we used digital image-processing technology to count the area ratios of the mortar and asphalt on the fracture surfaces.

Digital imaging uses numerical values to represent the surface of an object, and pixel points divide the object surface into discrete units, where the quantized gray numerical values represent the gray level. Digital image-processing consists of processing a series of values in the digital imager to obtain the desired result. Numerical image-processing technology can be used to perform image preprocessing, image segmentation, image expression, image pattern recognition, and feature extraction to analyze digital images. This analysis technique uses two main methods: spatial processing and frequency domain processing. In spatial processing, the operation is conducted on the pixels in the image, while in frequency domain processing, the numerical image is converted into a two-dimensional function to create other orthogonal coordinate bases for corresponding processing. In this study, we utilized airspace processing technology [28].

\section{Results and Discussion}

\subsection{Pull-Off Test Results}

In this work, 45 groups of pull-off tests were conducted, and the test results were as follows (Figure 7). 


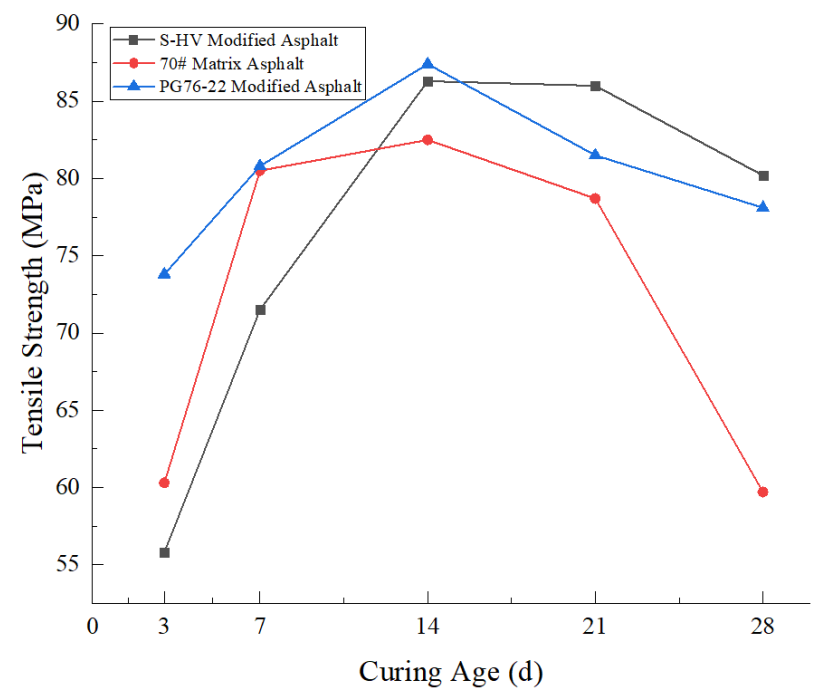

Figure 7. The tensile strengths of the three bitumen materials with the curing age.

When the water/powder ratio of the cement mortar was 0.23 , three types of asphalt were used as the cement agents for curing times of 3 and $7 \mathrm{~d}$. The order of interfacial tensile strength followed: PG76-22 modified asphalt $>$ 70\# petroleum asphalt $>$ S-HV modified asphalt. At curing times of 21-28 d, the interfacial tensile strength of the specimens with 70\# petroleum asphalt as the cementing agent decreased rapidly, and the strength was the lowest among the three asphalt types. This was attributed to the 70\# petroleum asphalt, which was not as dense and durable as the other two asphalts. Moisture can also penetrate the asphalt faster, causing asphalt emulsification and interfacial bonding failure. When the S-HV modified asphalt was used as an interfacial binder, the tensile strength of the interface increased rapidly during the early stages of curing, and reached an average standard after $14 \mathrm{~d}$, which was the peak tensile strength.

In summary, we found that during the early stages of curing, moisture ingress into the mortar accelerated the hydration of the mortar and enhanced its strength. As a result, the tensile strength of the interface increased with increased aging time and, during the later stages of curing, moisture ingress caused the asphalt to emulsify. In addition to the failure of the asphalt-granite interfacial bond, both conditions can cause a decrease in the tensile strength of the interface.

\subsection{Image Processing and Analysis of Fracture Surface}

Three materials with different colors appeared on the fracture surface, namely, asphalt, the interface, and the mortar, as shown in Figure 8, where the gray-black dots in the image are asphalt, the interface is dark brown, and the gray-white material is the mortar.

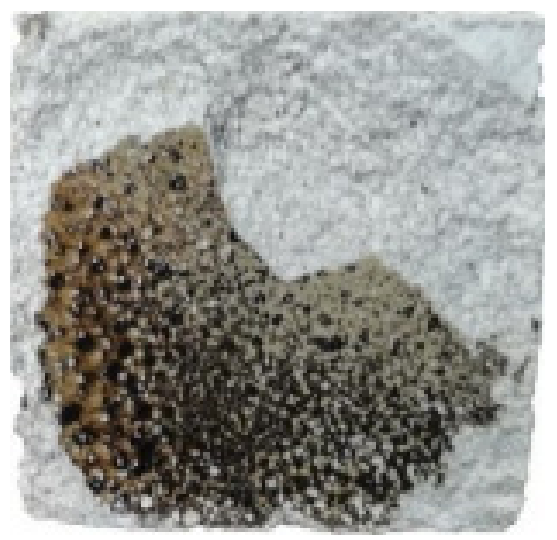

Figure 8. Fracture surface of the specimen. 
We first conducted image preprocessing. Due to the noise in the spatial domain while acquiring the digital images, the images had distorted details, which caused large errors in image analysis. To reduce the effect of noise on the digital images, we preprocessed the digital images before conducting the analysis. In this work, we used denoising, image enhancement, and other imaging technologies to process the digital fracture surface image. Some studies have indicated that the use of wiener filtering and median filtering to denoise digital images may also provide a good denoising effect [29]. The image-processing results are shown in Figure 9. After image noise reduction, the images were blurred at the junction of the two substances, causing large errors in image segmentation. Therefore, after the denoising process, the images were enhanced, to remove irrelevant information and enhance regional contrast.

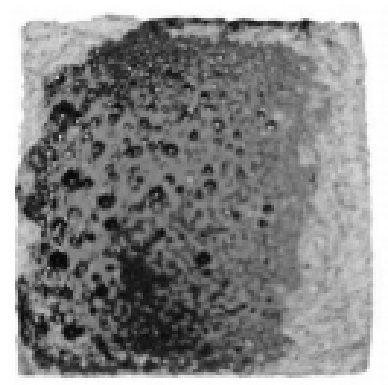

(a)

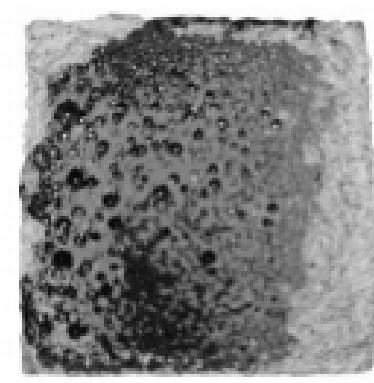

(b)

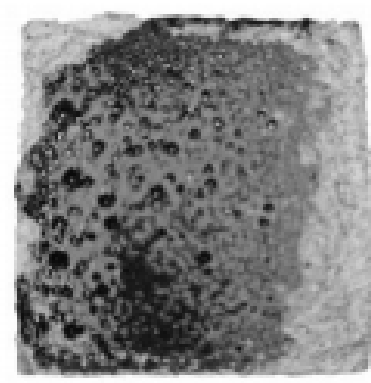

(c)

Figure 9. Image preprocessing, (a) Gray processing, (b) Wiener filtering, (c) Median filtering.

Next, we used image grayscale and threshold selection, using MATLAB 2018 software to analyze and process the digital images to show the fracture surface. The seconddeveloped program, as well as the original software, were used to analyze and process the pixels in the images. A grayscale image was regarded as a two-dimensional function of $f(x, y)$, where $(x, y)$ represented the spatial plane coordinates, and the function value $f$ represented image brightness, which was termed "gray", to express the brightness of each image. Each $(x, y)$ coordinate point in the image corresponded to a gray value, and image information and gray values for all the coordinate points in the image were used to form a digital image. This was denoted as a digitization of the coordinate values by sampling, and the digitization of the gray values was denoted by quantization.

The gray values for each coordinate point were divided into 266 small divisions, ranging from pure black to pure white, and were represented by values ranging from 0 to 255, where 0 indicated pure black and 255 indicated pure white. When taking a photo, the gray value displayed on the picture was different because of varying luminous flux, which was reflected by the different materials. On this basis, we analyzed the gray values on the coordinate point to determine the composition and area ratio of the materials in the photos. Non-linear, linear, and piecewise linear transformations were the most-used gray-scale transformation methods.

This work utilized the three-stage piecewise linear transformation method for piecewise linear transformation to divide the asphalt, interface, and mortar on the fracture surface into different gray levels. We obtained 10 pictures of the mortar, interface, and asphalt sections in the different fracture surfaces, as shown in Figure 10. The statistical analysis results showed that the mortar on the fracture surface was gray-white, with a gray range of $\sim 160-255$, and the interface was gray, with a gray range of 100-160, and the asphalt was gray-black, with a gray range of 0-100. 


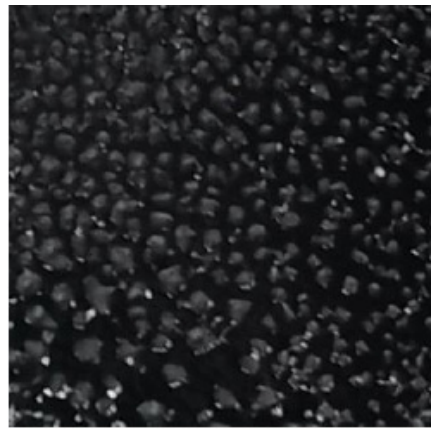

Asphalt

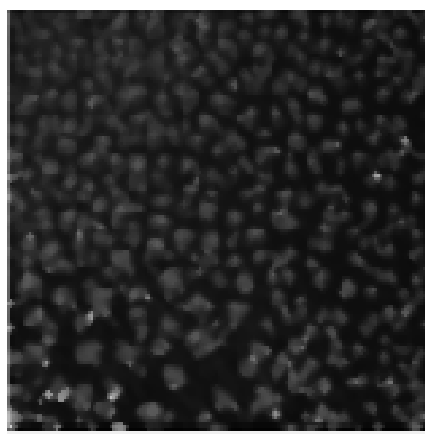

Asphalt

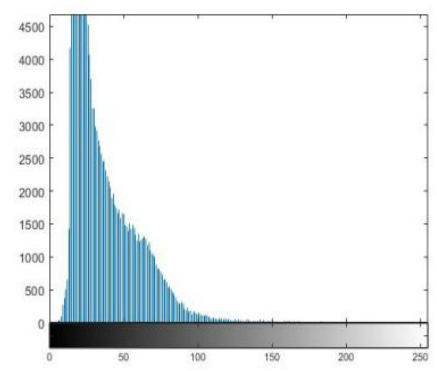

Asphalt

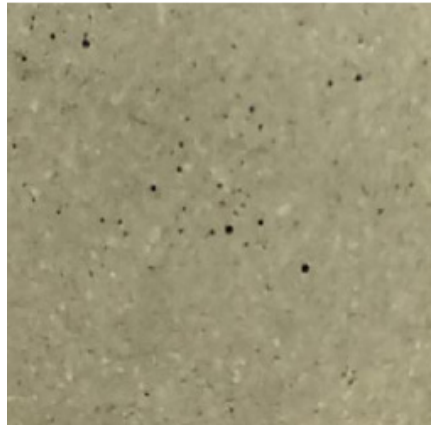

Interface

(a)

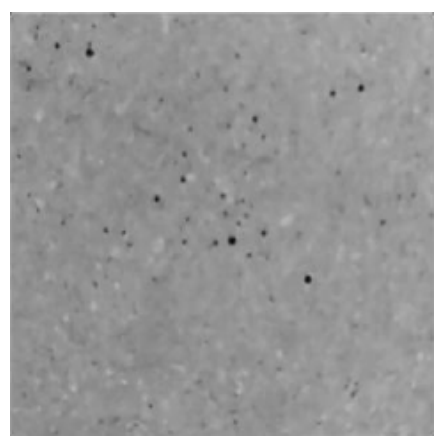

Interface

(b)

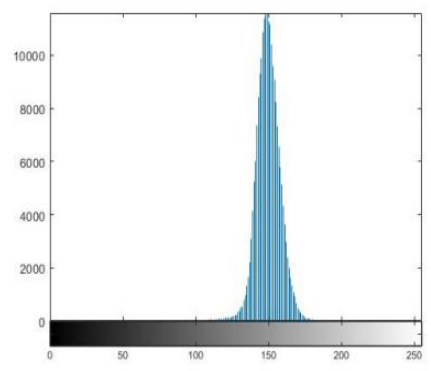

Interface

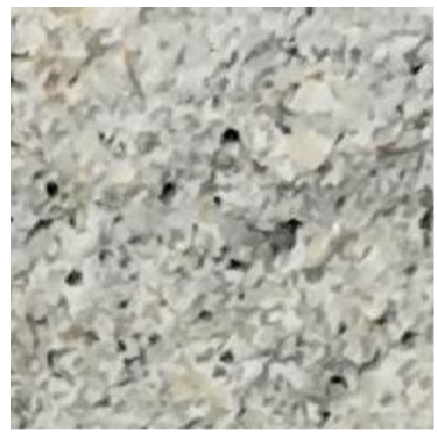

Mortar

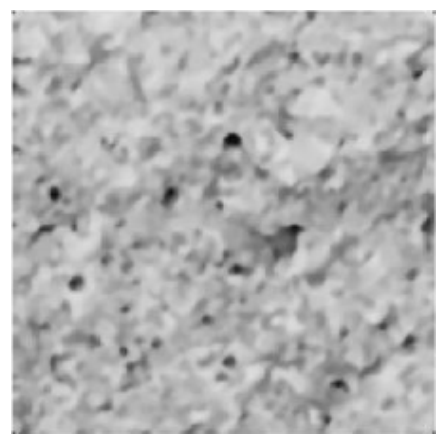

Mortar

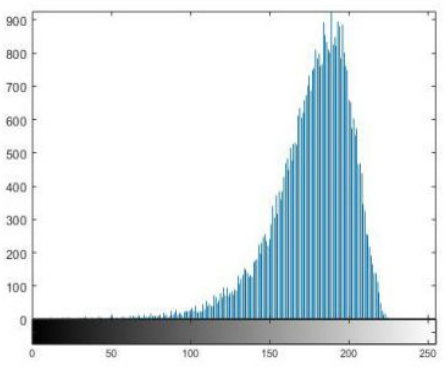

Mortar

(c)

Figure 10. Picture processing of the asphalt, interface, and mortar materials. (a) Original image, (b) Gray image, (c) Gray histogram.

This work also calculated the proportion of the asphalt and mortar area, showing that the three types of asphalt binder on the granite fracture surfaces varied with curing age, as shown in Figure 11. After three days, the specimens with 70\# petroleum asphalt and mortar fractured during the test, because of the insufficient tensile strength of the mortar.

As shown in Figure 11, for the specimens cured for three days, the mortar accounted for the largest area. Except when using PG76-22 as a binder, the asphalt area accounted for the smallest proportion. The mortar area proportion continued to decline with increasing curing age [30,31], possibly for the following reasons. As the curing age increased, the hydration reactions in the cement mortar continued, and the tensile strength of the cement mortar increased, resulting in a decrease in the potential mortar fracture performance of the specimen when subjected to tensile testing. As the curing age increased, the interactions between the asphalt and mortar increased, which increased the stress range of the mortar, resulting in cracks at the interface. Finally, with prolonged curing time, the continuous 
intrusion of moisture caused the asphalt to emulsify, which caused the failure in interfacial bonding and caused the asphalt to crack at the interface.

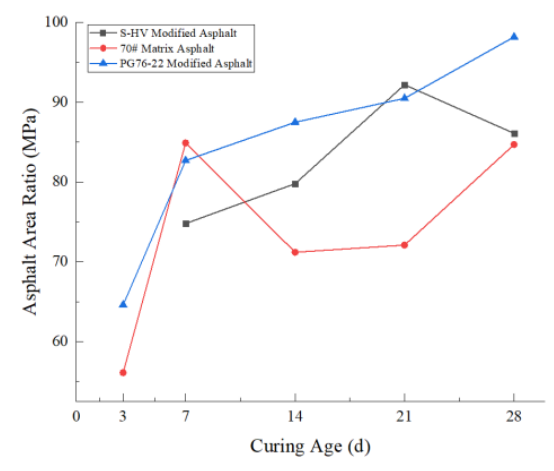

(a)

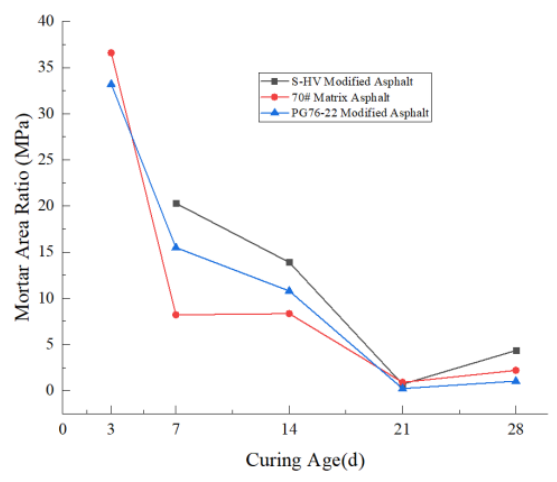

(b)

Figure 11. Changes in area ratio with curing age. (a) Changes in asphalt area with curing age, (b) Changes in mortar area with curing age.

The asphalt area accounted for the overall upward trend with prolonged aging time. The area ratio of asphalt dropped suddenly after $14 \mathrm{~d}$, when PG76-22 was used as the interfacial binder. Quartz was present on the granite surface, and the adhesion of quartz and asphalt is poor; thus, the asphalt peeled off when the quartz was pulled, and the proportion of asphalt area suddenly decreased. Then, owing to the emulsification of the asphalt, the cohesive forces of the asphalt itself decreased, causing the asphalt to eventually fracture.

As noted in Figure 12, when we used 70\# petroleum asphalt, many small folds were observed in the asphalt on the fracture surface of the specimen in the early stages, and the materials started to pull apart. This indicated that when the test piece was cured for three days, the cohesive forces of the mortar and 70\# petroleum asphalt were already greater than the cohesive forces of the 70\# petroleum asphalt. Therefore, for the specimens containing 70\# petroleum asphalt, and at curing times of 3-14 d, the mortar strength controlled the tensile strength of the specimen interface. With a prolonged curing time, the strength of the mortar increased, and the tensile strength of the interface increased. After $14 \mathrm{~d}$ of curing, the interfacial tensile strength was dominated by the cohesion of the asphalt. With an increased curing time, moisture continued to invade the asphalt, causing the asphalt to emulsify and reducing its cohesive properties, causing a decrease in the tensile strength of the specimen interface. Therefore, when using 70\# asphalt as a binder for semi-flexible pavement construction, it should be not applied to areas which receive an excessive amount of rain. As a result, we recommend that road access be restricted for at least three days, before the semi-flexible pavement is made accessible to traffic.

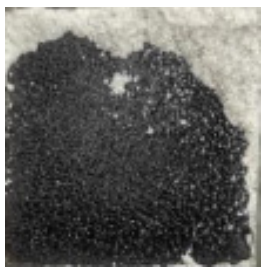

(a)

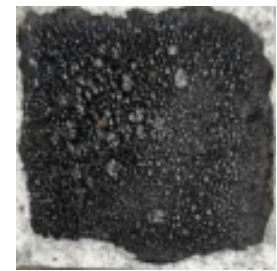

(b)

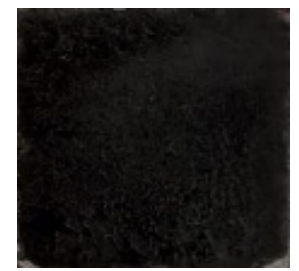

(c)

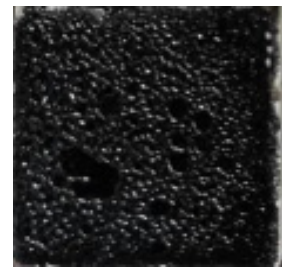

(d)

Figure 12. Changes in fracture surface with increased curing age (using 70\# petroleum asphalt). (a) 3d, (b) 7d, (c) 14d, (d) 21d, (e) 28d.

As shown in Figure 13, when we used PG76-22 modified asphalt, which was cured for three days, the asphalt surface on the fractured surface was still relatively smooth. 
This indicated that when the interface was cracked, the bonding and interactions of the asphalt and mortar were poor, and the interfacial tensile strength of the specimen was mainly dominated by the strength of the mortar. After curing for seven days, bonding failure of the asphalt and aggregate interface occurred, with wrinkles in the asphalt when the asphalt broke. In addition, the tensile strength of the specimen interface was mainly dominated by the adhesion of the asphalt and the aggregate interface. After curing for $14 \mathrm{~d}$, interfacial failure between the asphalt and aggregate became more noticeable. At this point, the tensile strength of the interface was mainly controlled by the adhesion capacity of the asphalt and aggregate. As the cohesive forces of asphalt and mortar and the cohesive forces of the asphalt itself are greater than the cohesive forces between the asphalt and the granite, the proportion of asphalt area was reduced when the interface fractured. After $21 \mathrm{~d}$ of curing, the bonding failure of the asphalt and aggregate interface was reduced and, after $28 \mathrm{~d}$, the bonding failure between the asphalt and the aggregate interface completely disappeared. The wrinkles were caused by the self-cohesive forces of the asphalt surface, which appeared when the asphalt cracked. In short, starting at $21 \mathrm{~d}$ of curing, the tensile strength of the specimen interface was mainly controlled by the cohesive forces of the asphalt. This result was attributed to two reasons. First, with the continuous ingress of moisture into the asphalt, the cohesion of the asphalt emulsification decreased. Second, with increased aging time, the interactions between mortar and asphalt increased. Therefore, when we used PG76-22-modified asphalt as a semi-flexible pavement interfacial binder, water damage resistance was stronger compared to the 70\# petroleum asphalt, but was greatly affected by the adhesion of aggregate and asphalt. Therefore, the adhesion capacity between the aggregate and asphalt should be carefully considered when building roads, and after road construction, we recommend a curing time of more than seven days.

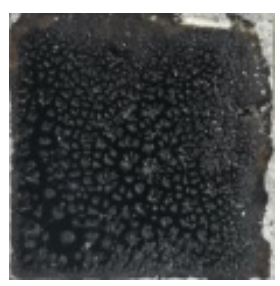

(a)

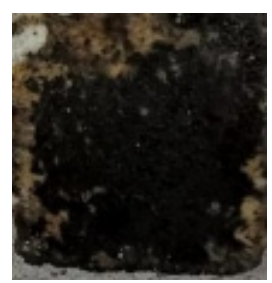

(b)

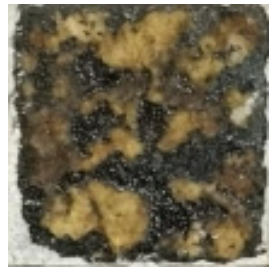

(c)

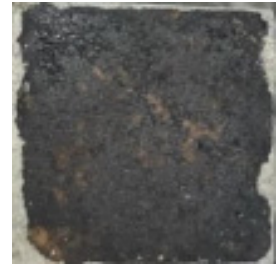

(d)

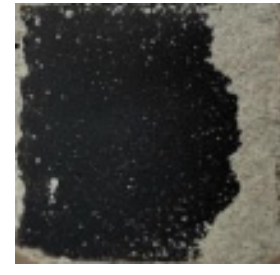

(e)

Figure 13. Changes in fracture surface with increased curing age (using PG76-22 modified asphalt). (a) $3 \mathrm{~d}$, (b) $7 \mathrm{~d}$, (c) $14 \mathrm{~d}$, (d) $21 \mathrm{~d},(\mathbf{e}) 28 \mathrm{~d}$.

As shown in Figure 14, when the S-HV modified asphalt was used as a binder, the asphalt to mortar ratio curve was similar to curing age over time. Before seven days of curing, the interfacial tensile strength was mainly controlled by the strength of the mortar and the bonding forces between the asphalt and the mortar. After curing for $14 \mathrm{~d}$, the asphalt portion in the fracture surface started to wrinkle, indicating that the interactions and adhesion between asphalt and mortar weakened. The wrinkles produced during the time were larger, but did not cover all the asphalt, indicating that the adhesion between the asphalt and the interface was less than the cohesive forces of the asphalt. Between 7 and $14 \mathrm{~d}$ of curing, the interfacial tensile strength was mainly dominated by the adhesion between the asphalt and the mortar, due to insufficient interfacial cohesion between the asphalt and the mortar. Starting at $14 \mathrm{~d}$ of curing, the interfacial tensile strength was mainly controlled by the cohesion between the asphalt. This was due to the increased interactions between the asphalt and the mortar and the ingress of water into the asphalt, which caused the asphalt to emulsify and reduced the cohesion of the asphalt. Therefore, when S-HV modified asphalt was used as a semi-flexible pavement interfacial binder, its ability to resist water damage was better than the 70\# petroleum and PG76-22-modified asphalt. However, if the road is to be opened to traffic afterward, we recommend a curing time of longer than $14 \mathrm{~d}$. 


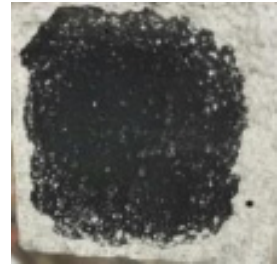

(a)

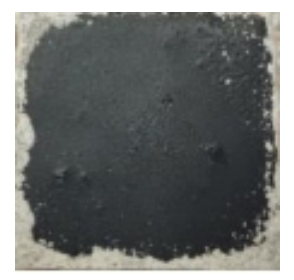

(b)

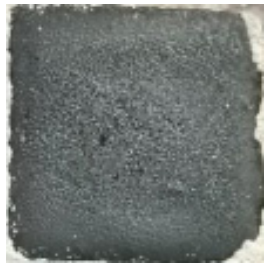

(c)

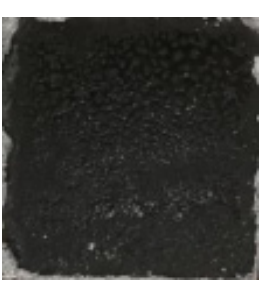

(d)

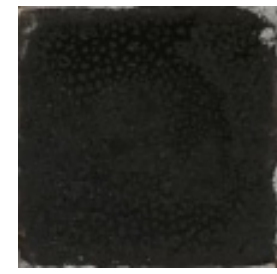

(e)

Figure 14. Changes in fracture surface with increased curing age (using S-HV modified asphalt). (a) $3 \mathrm{~d}$, (b) $7 \mathrm{~d}$, (c) $14 \mathrm{~d}$, (d) $21 \mathrm{~d},(\mathbf{e}) 28 \mathrm{~d}$.

In summary, the curing times required for the three asphalt and mortar types to achieve better interactions and adhesion in the SFP were as follows. Before three days of curing, 70\# petroleum asphalt and mortar achieved better interactions and adhesion. Between three and seven days of curing, PG76-22-modified asphalt and mortar achieved better interactions and adhesion. However, between 14 and $21 \mathrm{~d}$ of curing, the S-HV-modified asphalt and mortar exhibited better interactions and adhesion. Therefore, the order of interfacial water damage resistance of the specimens with different asphalt materials as binder was as follows: S-HV-modified asphalt > PG76-22-modified asphalt > 70\# petroleum asphalt.

\section{Conclusions}

In this work, different types of asphalt were used as interfacial binders according to pull-off, tensile strength measurements, and fracture surface image analysis, and the following conclusions were drawn.

When using PG76-22-modified asphalt as the interface binder, the maximum tensile strength of the interface was larger than specimens with 70\# asphalt as the binder. However, the interfacial tensile strength was lower with less curing time. When the S-HV modified asphalt was used as an interfacial binder, more curing time was required for the specimen interface to reach peak tensile strength. The order of peak tensile strength values for the interfacial materials was as follows: PG76-22-modified asphalt $>70 \#$ petroleum asphalt $>\mathrm{S}$-HV-modified asphalt.

On the fracture surface, the mortar was gray-white, the gray-scale range was 160-255, the interface was gray, with a gray-scale range of $100-160$, and the asphalt was gray-black, with a gray-scale range of $0-100$.

The curing times required for the three asphalts and mortar types to achieve improved interactions and adhesion were as follows: the 70\# petroleum asphalt required $3 \mathrm{~d}$ of curing, PG76-22-modified asphalt required $7 \mathrm{~d}$ of curing, and S-HV-modified asphalt required $21 \mathrm{~d}$ of curing. In addition, the order of interfacial specimen water damage resistance, with different asphalt types was as follows: S-HV-modified asphalt >PG76-22-modified asphalt $>70 \#$ petroleum asphalt.

Author Contributions: Funding acquisition, K.W.; Writing: Original draft preparation, X.L. and K.W.; Writing: Review and editing, W.H. and X.C.; Methodology, J.Y. and G.N. All authors have read and agreed to the published version of the manuscript.

Funding: This research was funded by the National Natural Science Foundation of China, grant number 51878193.

Informed Consent Statement: Not applicable.

Conflicts of Interest: The authors declare no conflict of interest.

\section{References}

1. Ke Zhong, B.C. Summary of Research and Application of Pouring Semi-flexible Pavement Materials. J. China Foreign Highw. 2017, 37, 232-235.

2. Mayer, J.; Thau, M. Jointless pavements for heavy-duty airport application the semi-flexible approach. Int. Air Transp. Conf. 2001, 87-100. 
3. Al-Qadi, I.L.; Gouru, H.; Weyers, R.E. Asphalt Portland Cement Concrete Composite: Laboratory Evaluation. J. Transp. Eng. 1994, 120, 94-108. [CrossRef]

4. Ling, T.Q.; Zheng, X.W.; Ling, M.; Xiong, C.H.; Dong, Q. Research on Performance of Water-retention and Temperature-fall Semi-flexible Pavement Material. China J. Highw. Transp. 2010, 2.

5. Hassani, A.; Taghipoor, M.; Karimi, M.M. A state of the art of semi-flexible pavements: Introduction, design, and performance. Constr. Build. Mater. 2020, 253, 119196:1-119196:25. [CrossRef]

6. Larsen, P. Reinforced Semi Flexible Pavement. U.S. Patent Application US 20040101365 A1, 27 May 2004.

7. Cai, X.; Fu, L.; Zhang, J.; Chen, X.; Yang, J. Damage analysis of semi-flexible pavement material under axial compression test based on acoustic emission technique. Constr. Build. Mater. 2020, 239, 117773:1-117773:10. [CrossRef]

8. Matzenmiller, A.; Gerlach, S. Parameter identification of elastic interphase properties in fiber composites. Compos. Part B Eng. 2005, 37, 117-126. [CrossRef]

9. Kawamura, N.; Morikawa, Y.; Murayama, M.; Hirato, T.; Maekawa, R. Durability of high-stability asphalt mixture under aircraft loading. In Proceedings of the 2014 FAA Worldwide Airport Technology Transfer Conference, Galloway, NJ, USA, 5-7 August 2014. Technical Papers.

10. Hassan, K.; Setyawan, A.; Zoorob, S. Effect of cementitious grouts on the properties of semi-flexible bituminous pavement. In Performance of Bituminous and Hydraulic Materials in Pavements; Routledge: Abingdon, UK, 2002; pp. 113-120.

11. De Beer, M.; Maina, J.W.; Netterberg, F. Mechanistic modelling of weak interlayers in flexible and semi-flexible road pavements: Part 2. J. South Afr. Inst. Civ. Eng. 2012, 54, 31-42.

12. Hamid, N.B.A.A.; Koting, S.; Karim, M.R.; And, H.B.M. Mechanical properties of cement-bitumen composites for semi-flexible pavement surfacing. Balt. J. Road Bridge Eng. 2014, 9, 191-199.

13. Hamzani; Munirwansyah; Hasan, M.; Sugiarto, S. Determining the properties of semi-flexible pavement using waste tire rubber powder and natural zeolite. Constr. Build. Mater. 2021, 266, 121199:1-121199:8. [CrossRef]

14. Afonso, M.L.; Dinis-Almeida, M.; Pereira-de-Oliveira, L.A.; Castro-Gomes, J.; Zoorob, S.E. Development of a semi-flexible heavy duty pavement surfacing incorporating recycled and waste aggregates-Preliminary study. Constr. Build. Mater. 2016, 102, 155-161. [CrossRef]

15. Cihackova, P.; Hyzl, P.; Stehlik, D.; Dasek, O.; Šernas, O.; Vaitkus, A. Performance characteristics of the open-graded asphalt concrete filled with a special cement grout. Balt. J. Road Bridge Eng. 2015, 10, 316-324. [CrossRef]

16. Corradini, A.; Cerni, G.; D'Alessandro, A.; Ubertini, F. Improved understanding of grouted mixture fatigue behavior under indirect tensile test configuration. Constr. Build. Mater. 2017, 155, 910-918. [CrossRef]

17. Read, J.M.; Collop, A.C. Practical fatigue characterization of bituminous paving mixture. Asph. Yearb. 1997, 66, 74-108.

18. Dave, E.V.; Hoplin, C. Flexible pavement thermal cracking performance sensitivity to fracture energy variation of asphalt mixtures. Road Mater. Pavement Des. 2015, 16, 423-441. [CrossRef]

19. Jiang, Y.; Xue, J.; Chen, Z. Influence of volumetric property on mechanical properties of vertical vibration compacted asphalt mixture. Constr. Build. Mater. 2017, 135, 612-621. [CrossRef]

20. Jahanbakhsh, H.; Karimi, M.M.; Nejad, F.M.; Jahangiri, B. Viscoelastic-based approach to evaluate low temperature performance of asphalt binders. Constr. Build. Mater. 2016, 128, 384-398. [CrossRef]

21. Cai, X.; Zhang, J.; Zhang, H.; Yao, Z.; Chen, X.; Yang, J. Identification of microstructural characteristics in semi-flexible pavement material using micromechanics and nano-techniques. Constr. Build. Mater. 2020, 246, 118426:1-118426:12. [CrossRef]

22. Hou, S.; Xu, T.; Huang, K. Investigation into engineering properties and strength mechanism of grouted macadam composite materials. Int. J. Pavement Eng. 2015, 17, 878-886. [CrossRef]

23. Xu, Y.; Jiang, Y.; Xue, J.; Tong, X.; Cheng, Y. High-Performance Semi-Flexible Pavement Coating Material with the Microscopic Interface Optimization. Coatings 2020, 10, 268. [CrossRef]

24. Zhou, L. Temperature Adaptability and Failure Mode Analysis of Semi-Flexible Composite Pavement. Ph.D. Thesis, Chongqing Jiaotong University, Chongqing, China, 2016.

25. Ministry of Transport. Standard Test Methods of Bitumen and Bituminous Mixtures for Highway Engineering; JTG E20-2011; China Communications Press: Beijing, China, 2011.

26. Yang, Y.; Huang, S.L.; Ding, Q.J.; Peng, X.Y. The Property Research on Interfacial Modificated Semi-Flexible Pavement Material. Appl. Mech. Mater. 2011, 71-78, 1090-1098. [CrossRef]

27. Shaanxi Academy of Building Research. Standard for Test Method of Basic Properties of Construction Mortar; JGJ/T 70-2009; China Construction Industry Press: Beijing, China, 2009.

28. Wang, Y. Computer Image Processing and Recognition Technology; Higher Education Press: Beijing, China, 2001.

29. Aliha, M.R.M.; Behbahani, H.; Fazaeli, H.; Rezaifarb, M.H. Rezaifar. Study of characteristic specification on mixed mode fracture toughness of asphalt mixtures. Constr. Build. Mater. 2014, 54, 623-635. [CrossRef]

30. Han, S.; Li, W.; Liu, M.; Liu, Y.; Ma, Y. Analysis of Adhesion of Asphalt Mixed with Hydrated Lime Based on Surface Energy. J. Jiangsu Univ. Nat. Sci. Ed. 2020, 41, 6.

31. Li, L. Road Engineering Materials, 5th ed.; China Communications Press: Beijing, China, 2010. 